WS13-01

\title{
Practical Core Interpretation for Input to Deterministic Facies Modelling in Wave- dominated Deltaic Reservoirs
}

\author{
R.J. Porter* (Nederlandse Aardolie Maatschappij B.V.) \& B. Bashokooh \\ (Nederlandse Aardolie Maatschappij B.V.)
}

\section{SUMMARY}

The main purpose of this workshop is to highlight the significance of 'traditional' reservoir geology skills. Sedimentology, reservoir properties and log signatures will be combined in a practical approach to define reservoir genetic units (flow units), using a wave-dominated deltaic example.

To emphasise the added value of this method, the results of a hands-on flow unit definition exercise using deltaic core material from the Book Cliffs, Utah, can be compared with a definitive answer. This is provided by a set of large-scale outcrop photo panels and Petrel static models which exactly define the sedimentary geometry and architecture of a field-scale exposure of fluvio-deltaic deposits. Participants can therefore judge the importance of the decision making processes such as deciding facies type, and the effect this could have on different reservoir geometries and architecture.

Through a combination of lectures, correlation exercises and a hands-on core description/interpretation exercise, it will be shown that combining sedimentology and sequence stratigraphy with regional palaeogeographical knowledge, can provide a robust deterministic framework for 3D reservoir models, that accurately predict reservoir architecture and connectivity ahead of drilling. 


\section{Amsterdam '14}

\section{Introduction}

Core is expensive, but allows physical contact with a reservoir, thus enabling direct measurement of properties such as porosity and permeability. It also allows observation of grain size, grain sorting and sedimentary structures which are used by sedimentologists to interpret different depositional environments (facies). Facies are then used in 3-D static models to assign sediment body geometry and architecture (size, shape and interconnectedness). In addition, core can be directly calibrated with $\log$ signatures so that facies can be accurately identified in the uncored wells.

\section{Objectives and format}

The main purpose of this workshop is to highlight the significance of 'traditional' reservoir geology skills. Sedimentology, reservoir properties and log signatures will be combined in a practical approach to define reservoir genetic units (flow units), using a wave-dominated deltaic example.

To emphasise the added value of this method, the results of a hands-on flow unit definition exercise using deltaic core material from the Book Cliffs, Utah, can be compared with a definitive answer. This is provided by a set of large-scale outcrop photo panels and Petrel static models which exactly define the sedimentary geometry and architecture of a field-scale exposure of fluvio-deltaic deposits. Participants can therefore judge the importance of the decision making processes such as deciding facies type, and the effect this could have on different reservoir geometries and architecture.

Through a combination of lectures, correlation exercises and a hands-on core description/interpretation exercise, it will be shown that combining sedimentology and sequence stratigraphy with regional palaeogeographical knowledge, can provide a robust deterministic framework for 3D reservoir models, that accurately predict reservoir architecture and connectivity ahead of drilling.

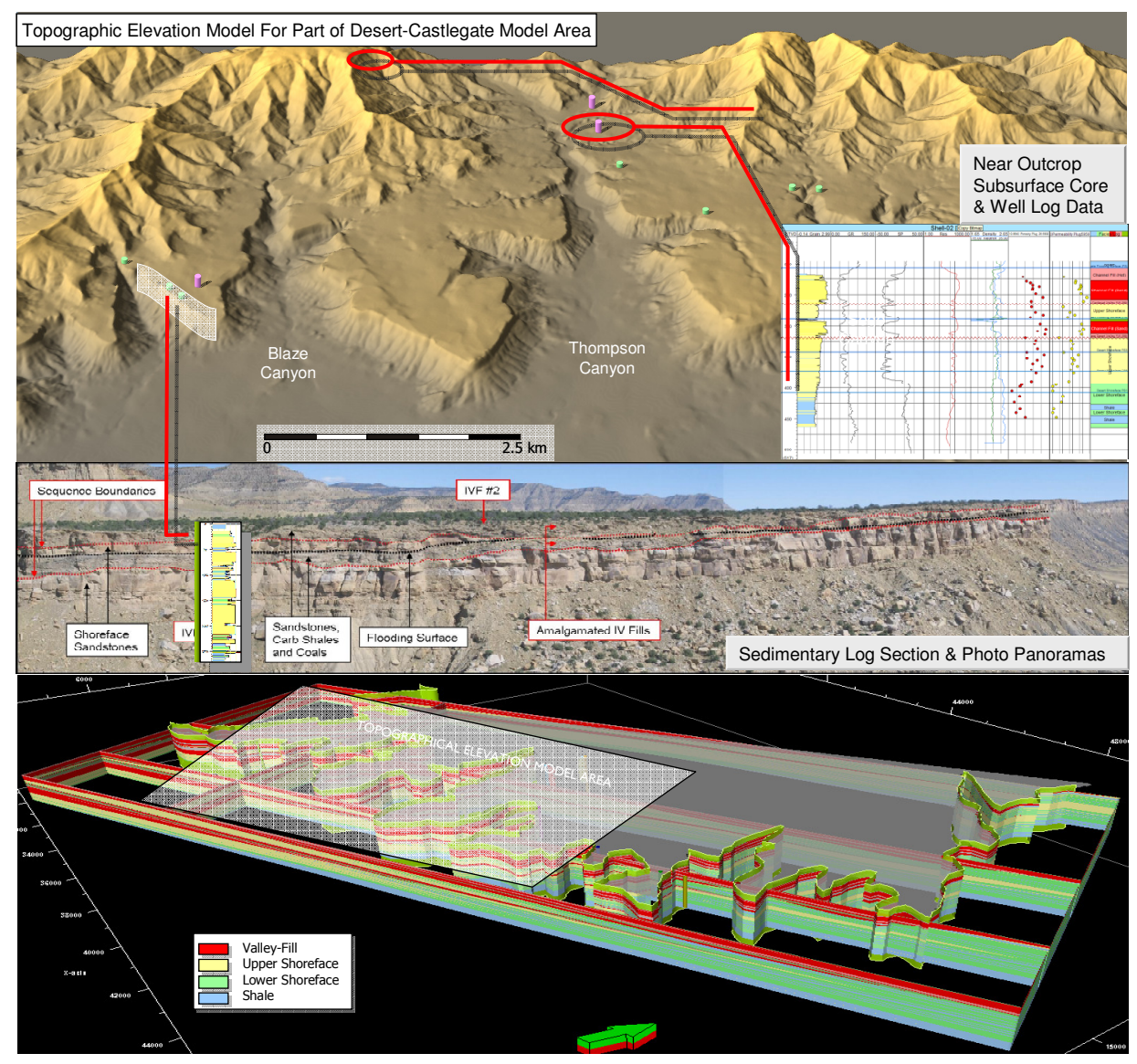

